primitive concepts (such basic quantifiers as one/another) from mental operations emerging in only one of these species.

However, the book does not attempt to represent evolutionary psychology as a whole. There is no coverage of the burgeoning literature on mate-choice or altruism, for example. 'Mind' is interpreted as the 'higher' cognitive functions, with two chapters devoted to reasoning, two to numeracy and two to language. Even here, there is no attempt to be comprehensive; cognitive mapping, tool use or cultural learning, for example, are not included. Since the rationale for this selectivity is not explained, the book has the feel of being a whimsical sampling of current thought on the evolution of mind. Thus, although the well-written chapters could be read individually as introductions to their specific areas, the book is not an overview for students. That said, some contributions are original and merit the attention of advanced scholars in both evolutionary psychology and related disciplines.

Some of the philosophers' contributions are unusually refreshing, particularly since they engage the concerns of practising scientists, as in Elliot Sobers' chapter on the appropriate interpretation of Lloyd Morgan's famous canon: "In no case may we interpret an action as the outcome of the exercise of a higher psychical faculty, if it can be interpreted as the outcome of the exercise of one which stands lower in the psychological scale."

Two chapters deal with the underlying rationale of evolutionary psychology more directly. Colin Allen and Eric Saidel build the case that although a certain cognitive structure may be uniquely human, the origins of at least some of its components may well be evolutionarily traceable. They illustrate this by examining the primate counterpart of language's ability to refer a listener to topics.

In the final chapter, Lawrence Shapiro identifies the core of evolutionary psychology: "what Darwin did for psychology is to license and ground the ascription of teleological functions to mental processes." Readers new to, or suspicious of, evolutionary psychology should perhaps read this chapter first.

Andrew Whiten is in the School of Psychology,

University of St Andrews, Fife KY16 9JU, UK.

\section{More on the mind}

Reaching into Thought: The Minds of the Great Apes

edited by Anne E. Russon, Kim A. Bard

\& Sue Taylor Parker

Cambridge University Press, $£ 24.95$

The Evolution of Consciousness

by Euan M. Macphail

Oxford University Press, £15.99, \$28

How the Mind Works

by Steven Pinker

Penguin, £9.99

\section{Earth's internally generated motions}

\section{Theoretical Global Seismology}

by F. A. Dahlen and Jeroen Tromp

Princeton University Press: 1998. 1,025 pp.

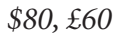

\section{Paul G. Richards}

Global seismology began in the 1880 s when the first teleseismic recording was made in Europe of an earthquake in Japan. For decades the subject developed as the study of the seismic body waves that propagate through Earth's deep interior, and the surface waves that are confined to the crust and upper mantle. Such waves can now be faithfully recorded across vast ranges of frequency, wavelength, distance and amplitude; and we study them for what they can tell us about the seismic source - perhaps an earthquake or an explosion - and about the Earth's structure through which they have travelled.

Since the underlying seismic motion can be quantified using linear wave equations, and since the Earth is a body of finite size, we know that all seismic motions of our planet can be expressed as a sum of the Earth's normal modes. Conceptually, every seismogram of every earthquake and explosion is a sum of the same set of decaying sinusoids, each of which begins its oscillation at every point of the planet when the earthquake begins. In practice, the set sums to zero until the first body wave arrives, and thereafter it is a representation of the ground motion at that recording station.

\section{New in paperback}

\section{At the Fringes of Science}

by Michael W. Friedlander

Westview Press, $£ 11.95, \$ 17$

The Call of Distant Mammoths: Why the Ice Age Mammals

\section{Disappeared}

by Peter D. Ward

Springer, $\$ 15, £ 11.50$

Colonialism and its Force of Knowledge: The British India

by Bernard S. Cohn

Princeton University Press, \$17.95, £12.95

The Astronomer's Universe

by Herbert Friedman

W. W. Norton, $\$ 14.95, £ 10.95$

Sir Aurel Stein: Archaeological Explorer

by Jeannette Mirsky

University of Chicago Press, \$20, $£ 15.95$

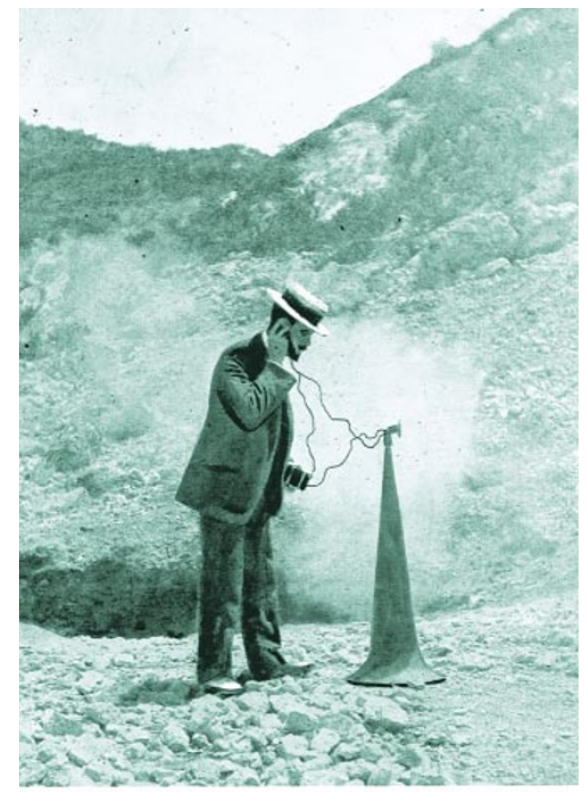

Communing with nature: a 1917 seismologist

listens to the rumbling of Italy's Solfatara volcano.

Theoretical Global Seismology by F. A. Dahlen and Jeroen Tromp consists of more than 1,000 pages and 10,000 equations and is motivated by the simplicity and elegance of this idea of mode summation. It is the first book to pull together the necessary details to address the complications arising from the fact that our planet departs slightly from elastic behaviour and is far from homogeneous.

First, the authors present the continuum mechanics that are needed to quantify features exhibited by the Earth - anelasticity, heterogeneity, anisotropy, high internal stress, rotation and spontaneous failures of

Redeeming Culture: American Religion in an Age of Science

by James Gilbert

University of Chicago Press, \$19, £15.25

The Kindly Dr. Guillotin: And Other Essays on Science and Life

by Harold J. Morowitz

Counterpoint, $£ 8.95, \$ 12.50$

Linear Programming and Extensions by George B. Dantzig

Princeton University Press, \$29.95, £23.95

From Savage to Negro: Anthropology and the Construction of Race, 1896-1954

by Lee D. Baker

University of California Press, \$17.95, £12.95

Fairweather Eden

by Michael Pitts \& Mark Roberts

Arrow, £8.99 
Hooke's law (otherwise known as earthquakes). Then they set out methods for quantifying the free oscillations of a spherically symmetrical Earth model, and show how these oscillations can be classified into groups that are affected by particular regions of the Earth's interior. Finally, they show how ellipticity and other forms of lateral variability can be handled.

Although the book's main emphasis is on normal modes, asymptotic methods are given to explain the principal features of body and surface waves. Most applications of seismology, including many of our discoveries about the Earth's internal structure, have been based on such asymptotic methods.

The book's presentation is authoritative, and graduate students and their supervisors for years to come will turn with gratitude to Theoretical Global Seismology to learn how to handle such complications as the effect of high initial deviatoric stress on the body force equivalent of an earthquake, or to interpret an accelerometer record at low frequencies when there can be significant contributions from changes in elevation (free air) and the overall gravity field.

Dahlen and Tromp's book shows us that seismology is a highly specialized science in that it focuses just on the internally generated motions of our planet. But, on the other hand, because we can study the Earth year after year and century after century, seismology also forces us to generalize our understanding of linear wave propagation. This we do in order to quantify the effects of inhomogeneity, high initial internal stress and discontinuities across a fault. Our new understanding is then available for other fields, for example waves in layered semiconductors.

The theoretical seismology in this book is not merely an intellectual achievement of a very high order, it is driven by the need to understand our planet and will be the basis of applied seismology and other practical studies of wave generation and propagation for decades to come.

Paul G. Richards is at the Lamont-Doherty Earth Observatory, Palisades, New York 10964, USA.

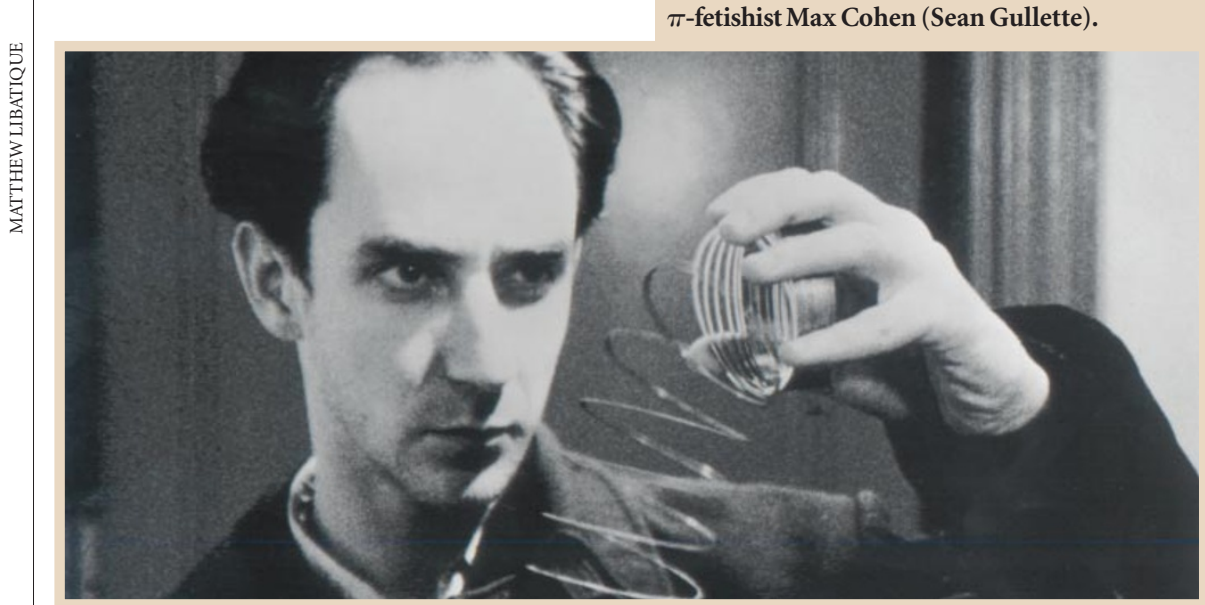

\section{Science in culture}

\section{$\pi$-fetishism}

$\pi$ : A Darren Aronofsky film

Artisan Entertainment: 1998

Graham Farmelo

$\pi$ is, I believe, the first film to be named after a mathematical symbol. This is a sign of the times: mathematics is seeping into popular culture, notably through books that have made Andrew Wiles's proof of Fermat's last theorem and the life of the number theorist Paul Erdös the stuff of recreational chatter.

No sooner have the educational Jeremiahs convinced us that mathematical standards in schools are both low and falling, at least in the West, than the subject becomes a big-business leisure activity among people who cheerfully admit they cannot cope with long division.

Hollywood discovered the new appeal of mathematics two years ago in the box-office hit Good Will Hunting, director Gus Van Sant's engaging tale of a delinquent mathematical genius. Set in Boston, the Athens of America, this was a surprisingly unsentimental portrayal of academic life in which mathematicians were for once played as more-or-less normal people and not as unkempt sociopaths with foreign accents as thick as treacle.

$\pi$ is more challenging fare, cinematically and mathematically. Like Good Will Hunting, it features a mathematician, but is - superficially at least - more concerned with how mathematics might be applied to the world. However, $\pi$ is not another crowd-pleasing blockbuster from the dream factory, but an accessible art-house film, produced from the independent sector. It first shot to notoriety after winning a Directing Award at the 1998 Sundance Film Festival.

Director and co-writer Darren Aronofsky sets his film in some of the more unsavoury parts of New York. The action revolves around the misanthropic number theorist Max Cohen (played by Sean Gullette), a certifiable $\pi$-fetishist and, of course, a genius (why do film-makers seem to think that all mathematicians are brilliant?). $\mathrm{He}$ works alone at home in his seedy little apartment, an Alfred Brendel of the computer keyboard,

$\pi$-fetishist Max Cohen (Sean Gullette). looking as if he's recovering from a lobotomy.

Cohen is convinced that the (almost random) digit sequence of $\pi$ holds the key to

understanding the pattern of daily changes in the New York stock market, which he monitors obsessively during his forays into the real world. "Mathematics is the language of nature," the narrator repeatedly intones, but Cohen does not bind himself to the rigours of scientific analysis, and so, as his mentor warns him, he is in danger of practising mere numerology.

As Max closes in on his solution, he is pursued by Wall Street hustlers intent on financial domination and by a Kabbalah sect trying to unlock the secrets behind their ancient holy texts. So we are in strange territory here, in the nether world of impure mathematics, tenuously connected to the real world via a 24 -carat eccentric and a host of gargoyles. You can't help feeling sorry for Cohen's neighbour: would you like to live next to someone whose work involves washing a human brain down his bathroom sink?

Aronofsky does not aim to give us a mathematics lesson, so he does not consider in any detail what has made the number $\pi$ such a rewarding mystery for mathematicians over the past 4,000 years. But he does gently try to interest us in the possibility of understanding the patterns we see around us. In one scene, Cohen looks out across a beach and we are invited to consider with him what might underlie the pattern of waves on the shore, of sea shells and of the light shimmering on the ocean.

Such quiescent moments are rare; $\pi$ is in the main a sharply cut thriller, suffused with a bleakness intensified by grainy black-and-white photography and the menacing electronic soundtrack. The script is taut, the production inventive and the direction striking. It all amounts to the most imaginative début for a writer-director since Quentin Tarantino gave us Reservoir Dogs.

But $\pi$ is not really about mathematics. Like Bertolt Brecht's Life of Galileo, which is less concerned with science than with the inability of a scientist to cope with the moral consequences of his work, Aronofsky's film uses his theme of mathematics-inspired hokum as a

backdrop for something different - an off-beat analysis of paranoia.

Now that mathematics is 'cool', its ideas have new currency in the arts. For me, this is both welcome and surprising. When I was an undergraduate, I attended an entertaining lecture on Principia Mathematica, Bertrand Russell and Alfred North Whitehead's mind-stretching account of the foundations of mathematics. But if Russell and Whitehead were so smart, our professor mused, why didn't they have the wit to sell the film rights? In 1973, that remark brought the house down. It wouldn't surprise me now if the laugh turns out to be on us. Graham Farmelo is at the Science Museum, South Kensington, London SW7 2DD, UK. 